\title{
Issues of Using Information Communication Technologies in Higher Education
}

\author{
Paul Oliver and Emma Clayes \\ University of the Highlands \& Islands, UK \\ paul.oliver.perth@uhi.ac.uk \\ emma.clayes.perth@uhi.ac.uk
}

\begin{abstract}
Social media sites such as Facebook and Twitter are examples of information communication technologies (ICTs) that have been widely adopted by students, and could potentially be useful as a resource for teaching and learning in further and higher educational institutions. Facebook tops the charts in social networking space, but when it comes to social messaging on mobiles WhatsApp walks away as the winner (Spohr, 2013). Facebook have recently purchased the popular social mobile app (Tech2, 2013). However, the use of social media has brought about numerous logistical issues and ethical issues relating to interactions with students. For example, the use of some tools in educational institutions is rather informal raising problems of accessibility and inclusion. Based on this phenomenon, we will conduct research to explore the usage of social networking sites and mobile social apps within further and higher education. We will use the survey method to ask students and staff their views on the use of this technology for learning and communication purposes. In this way we hope to compare the views of students in higher education on courses in Music Business and Psychology. While self-report methods are inherently subjective, we believe it is important to explore how both staff and students both use and view different features of these technological tools. Using focus groups, we hope to identify the main themes concerning the use of educational technology for staff and student groups. A larger sample will be obtained using a questionnaire to garner opinions on the main concerns raised. Analysing this data may help in providing recommendations for educational institutions, keeping in mind the important logistical and ethical issues some are unaware of.
\end{abstract}

Keywords: Information Communication Technologies, Higher Education, Social Media, Social Mobile Apps, Music, and Social Sciences

\section{Introduction}

The debate within higher education institutions (HEI) is rife talking about the issues surrounding the use of information and communication technologies (ICTs) for both students and staff interacting for social as well as educational purposes. However, there is a genuine lack of academic research in this area not just in the areas of Music and Social Sciences but also any other field for that matter (Garrison and Anderson, 2003; Gikas, 2013; Veletsianos, 2012).

The aim of this paper is to better understand the evolution and development of how ICTs are used in higher education, by both students and staff, and the practical and ethical issues that are associated with using these technologies.

\section{Literature Review}

\subsection{ICTs Defined}

ICTs are commonly defined as technologies that provide access to information through telecommunications. It is similar to information technology (IT), but focuses primarily on communication technologies.

This includes the Internet, wireless networks, cell phones, and other communication mediums (Tech Terms, 2014). The different types of ICTs include the following:

- Email

- Virtual learning environment (VLE)

- Social networking sites (SNS)

- Social mobile applications

- User-generated content sites 
- Video-conferencing and voice-over internet protocol (VoIP)

In the past few years, ICTs have provided society with a huge variety of new communication capabilities. For example, people can communicate in real-time with others in different countries using technologies such as instant messaging and video-conferencing. Social networking websites like Facebook (FB) allow users from all over the world to remain in contact and communicate on a regular basis.

\subsection{ICTs in Higher Education}

Until recently, there has been a definite lack of research conducted into the potential for integration of ICTs to help people learn in higher education (Garrison and Anderson, 2003). Despite the constant growth of ICTs, educators are only just beginning to comprehend the potential for technology to help students construct their own meaning through various learning activities (Eynon, 2005). Not only through the use of email and VLEsbut also social media sites.

It is now thought that ICT plays a vital role in the future of education in the UK and throughout the world (Tongkaw, 2013) and is an important catalyst and tool for inducing educational reforms that change our students into productive handlers of knowledge (Eynon, 2005). From qualitative (Fullan and Stiegelbauer, 1991) studies it has been often argued that staff development is a very crucial factor in the process of adopting and implementing ICTs in education. However, this is not something that is being addressed practically, and so the issues continue arise year-on-year.

\subsection{The Growth of Social Networking Sites}

Social networking sites (SNS) such as Facebook and Twitter are examples of ICTs that have been widely adopted by students outside of higher education institutions, as well as in, and could potentially be extremely useful as a resource for teaching and learning in the future. Despite a clear lack of academic research in this area, there is a plethora of online articles talking about issues of young people, and people in general, using social media and social mobile apps and the implications, which is surely where attention must be focused in terms of moving this debate forward relative to ICT use in higher education.

Facebook has been at the forefront of social networking for more than a decade, and recently celebrated its 10-year anniversary with its 1.23 billion online users, adding 170 million in just one year (Kiss, 2014). The site is now worth $\$ 135 b n$ with revenues of $\$ 7.87$ bn in 2013 , including $\$ 1.5 b n$ in profit. Globally, 556 million people now access the site every day on their smartphone or tablet and at the end of 2013, for the first time, Facebook made more than $\$ 1$ bn in revenue from mobile advertising in just one quarter (Kiss, 2014). Moreover, these billions of US dollars for buying a little app is one of the main critical issues of SNS because the users pay with their personal data.

However, in the last quarter of 2013 Facebook saw a "steady decrease in daily users, specifically among teens" (Olson, 2014), with several media outlets discussing the future of social networking and whether it still appears to a vital demographic. This means that teenagers are still on Facebook but they are just not using it as much.

\subsubsection{Facebook's Purchase of WhatsApp}

Facebook tops the charts in social networking space, but when it comes to social messaging on mobiles WhatsApp walks away as the winner (Khedekar, 2013). Figures clearly show that WhatsApp has been ahead of Facebook in terms of market share with $44 \%$ of the consumer demographic, as opposed to Facebook's inferior 35\% (Khedekar, 2013).

As a result, over the last few months Facebook have been in talks to buy out the popular social mobile app (Tech2, 2013) and a deal was done on $21^{\text {st }}$ February 2014 for an estimated cost of \$19 billion (Rush, 2014). However, Facebook is now being investigated by the Federal Trade Commission, with growing concerns over the threat to its 450 active users' privacy (Neal, 2014).

Therefore, despite a lack of academic research in the area of ICT use within higher education, there is much debate ensuing over issues of using social media and social mobile apps generally in everyday situations. 


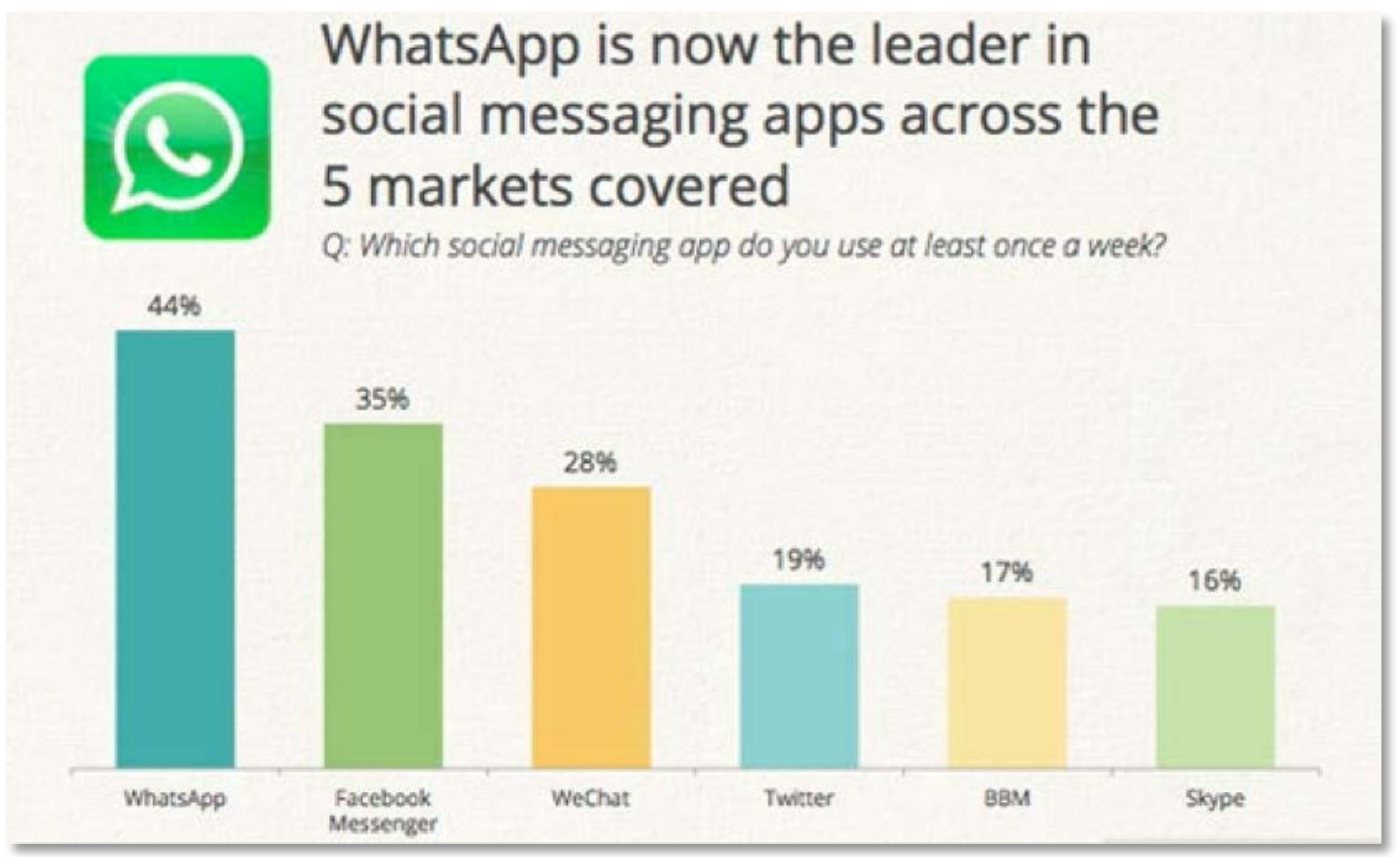

Figure 1. WhatsApp is now the leader in social mobile apps (Khedekar, 2013)

\subsection{Rationale}

We are interested in both usability and ethical issues, and comparing the views of students and staff. It appears that there is a dearth of studies examining staff views or indeed ethical issues, both in relation to ICTs, but specifically social media usage. Lin (2007) is one of the few studies to examine ethical issues in the use of technology in Higher Education and found that learning technologists were aware of issues surrounding privacy and accessibility although they were also concerned with the more common ethical concerns surrounding copyright and professionalism.

In terms of social media, Reynol (2013) found a complex relationship between use of Facebook and student engagement, as some Facebook activities were positive predictors of student engagement yet others were negative. This complex picture does not help to resolve the findings of a previous study by Reynol in 2012 which found that overall Facebook activity is negatively related to academic performance and time spent preparing for class.

Gikas and Grant (2013) carried out student focus group interviews to investigate student perspectives on communications technology including social media and found that while there was enthusiasm for increased interaction, and this highlights an emerging trend that goes beyond using the technology simply for accessing resources, students are concerned about the lack of formal training or support given by their institutions and interestingly are aware of the problems of distractions and blurring the lines between formal and informal learning. Deng and Tavares (2013) compared students views of Facebook and the online learning environment offered by the institution (Moodle) and found that while students were much more active on Facebook, it is not clear whether this is due to enhanced user interface features or whether it is a reflection of social bonds that result in more spontaneous and organic communication quite separate from the formal institution rules. The authors end with some interesting questions regarding the quality of communication in such different contexts.

While there seems a dearth of research relating to instructor views of social media, a review by Hew (2011) uncovered a number of interesting experimental studies on the effects of teacher information available online, while the few studies that surveyed teachers found that most found it useful for posting resources and the conclusions overall are that Facebook has very little educational use. 
Veletsianos and Kimmons (2013) carried out an interesting study on staff views of social networks using phenomenological interviews. The main conclusions highlighted important ethical concerns regarding personal and professional responsibilities, boundaries and concerns regarding the nature of communications online and whether this was an efficient use of time. This latter concern mirrors previous studies concerns from students regarding distractions online when using socialmedia.

We believe that the studies above highlight common concerns that have arisen regarding the use of social media in education, and that the ethics and views of staff involved are two areas that have been overlooked. To this end, we decided to compare students and staff views of ICTs, another issue is that studies are increasingly disparate due to focusing on specific new technologies arising, using a structured interview technique to highlight ethicalconcerns.

\section{Methodology}

The method used to carry out this study was the survey method, specifically focus groups designed to interview groups of four people (see information and consent form in appendix 1). The focus groups were designed to last around 15 minutes and were structured around the following questions:

1. What kind of communication technologies and/or mobile applications do you use?

2. What do you think are the benefits of communication technologies in education?

3. What do you think are the problems concerning the use of communication technologies in education?

4. What are the reasons you might not use specific types of communication technologies?

5. Do you think there are any ethical issues surrounding the use of communication technologies in education?

6. Are there any practical issues you think are important to consider when using these technologies in education

7. How do you think communication technologies could be improved for the purposes of education?

\subsection{Participants}

Quota sampling was used to target and recruit specific types of participants in order to fulfill the overall aims of this study. Two staff focus groups were conducted (one music, one social science) and four student focus groups were conducted (two music, two social sciences) at Perth College UHI (University of the Highlands \& Islands). One researcher led the focus groups from the respective subject areas asking identical sets of questions for each focus group. We thought it would be interesting to compare the views of students and staff from different curriculum areas in order to ascertain if there were common concerns out with specific curriculum areas.

\subsection{Materials}

Questions (see above) and information/consent forms were used. Focus groups were conducted in empty rooms in the college and suitable recording devices were used (recording applications on smartphone-Mini recorder and IPhone).

\subsection{Procedure}

Participants were approached and asked if they would like to take part in a group discussion at a mutually agreeable time- this was organised via email. Once a suitable date/time was agreed the researcher met the participants and gave out the information/consent forms to read and sign before the discussion took place. All participants were asked if they would like to ask any questions before the discussion started, all were made aware that the discussion would be recorded and all data would be treated with the utmost respect. There was no time limit although discussion was centred on questions posed.

\subsection{4 Results}

Due to the structured nature of the discussions, the results were gathered by identifying central themes arising from each question. 
The main themes from each group are summarised in Table 1 below. Only staff seemed majorly concerned about ethical issues such as inclusion in terms of all students being able to access the different types of technology used.

Interesting practical issues regarding ease of access as a large majority in all groups experienced problems accessing the institution's virtual learning environment (and email) and thus missing notifications from education technologies that seem much easier on social media sites. Nonetheless, many expressed concern at the increase of distractions when using social media in education.

\begin{tabular}{|c|c|c|}
\hline & Positives & Negatives \\
\hline $\begin{array}{l}\text { Staff (Music / } \\
\text { Social Sciences) }\end{array}$ & $\begin{array}{l}\text { Familiarity (applications/devices). } \\
\text { Access (Improved particularly when } \\
\text { using FB consequent to poor UHI } \\
\text { email). } \\
\text { Speed (ease of communication with } \\
\text { FB, messages received in timely } \\
\text { fashion). } \\
\text { Availability (Subject to usage). } \\
\text { Convenience }\end{array}$ & $\begin{array}{l}\text { Over familiarity of student/lecturer. } \\
\text { Increasing workload (multiple systems of } \\
\text { communication resulting in repetition). } \\
\text { Ethical dilemmas (over-familiarity, inclusion, } \\
\text { cyber-stalking). } \\
\text { Informality } \\
\text { Possible litigation. } \\
\text { Discipline. }\end{array}$ \\
\hline $\begin{array}{l}\text { HNC students } \\
\text { (Music / Social } \\
\text { Sciences) }\end{array}$ & $\begin{array}{l}\text { Access } \\
\text { Easier to hold discussions as can view } \\
\text { replies instantly on FB } \\
\text { Link to interesting content easily }\end{array}$ & $\begin{array}{l}\text { Distractions } \\
\text { Increased access to inappropriate content } \\
\text { Increase of unreliable information } \\
\text { Need to keep life and work separate }\end{array}$ \\
\hline $\begin{array}{l}\text { Degree students } \\
\text { (Music / Social } \\
\text { Sciences) }\end{array}$ & $\begin{array}{l}\text { Access } \\
\text { Keep up to date wherever you are, } \\
\text { Instantaneous, brings peer group } \\
\text { closer together } \\
\text { Direct link to all knowledge e.g. exam } \\
\text { timetables } \\
\text { Handing in work regardless of location, } \\
\text { admin cut down, much quicker }\end{array}$ & $\begin{array}{l}\text { Distractions } \\
\text { Formal/Informal nature- feel embarrassed to } \\
\text { post on discussion board and for lecturers to } \\
\text { see problems. }\end{array}$ \\
\hline
\end{tabular}

Table 1. Key themes arising from focus group discussions on use of social media in education

These results are interpreted in more detail with reference to individual quotes in the findings and discussion section.

\section{Findings and Discussion}

\subsection{Music Staff}

Music staff were generally positive about the use of ICTs in higher education, and regularly engage with social media:

"I will openly admit that I use Facebook with my students because they respond to that, and they know that if I want to get in touch with them ..."

"I think they're beneficial to students because that's the real world and that's the way it's moving ... it's a lot quicker and instant to speak to people using those technologies." 
However, there were reservations about how it is used to communicate with students:

"I'm on the other end of that [scale] we use Blackboard (virtual learning environment), that's how I communicate with my students. I'm not against using Facebook but it would have to be a specific Facebook page set up for the department."

One key issue is that the staff group expresses a concern for the practical issue of students not fully engaging with ICTs in higher education:

"It's amazing the number of students that still say 'I haven't got internet at home' ... I find it quite surprising that students are would say that."

Also, privacy is a reason for staff disengagement with social media, such as Facebook, worrying about the line that could be crossed between lecturer and student:

"Maybe privacy issues ... so you're not actually in control of that content I suppose."

"It's social media. It's called social media for a reason. It's for social purposes, not for educational purposes. Again, it is just privacy really..."

However, there was a clear split of opinion within the focus group about whether or not it is ethical to fully engage with students via social media, for example, accepting a Facebook request:

"I would because I would only use my [Facebook] page for two things with people here [at Perth College] or with dance, so I know there's no chance of another photo popping up."

"As soon as I started working here I cancelled my old Facebook page, just because there's just stuff that I wouldn't want students to see."

Overall, Music staff were positive about the use of ICTs, including the use of email and Blackboard in higher education, although there was a split opinion on how social media could and should be used within the higher education system. It was suggested that some kind of integration into the current virtual learning environment might be a possible long-term solution:

"I think it might be good if there was an app for Perth College UHI that would have you immediately into Blackboard and your email all in the one ... so that it's all integrated."

\subsection{Social Sciences Staff}

Social Sciences staff was also fairly positive regarding the use of ICTs in higher education, particularly social media, although some concerns arose particularly regarding the functionality of the institution's learning environment and that students must get used to virtual learning environment being offered:

"As a general thing is that we are supposed to be preparing students for the place of work so that does not mean they get to choose what they use at work. They will be told they are to use this, this and this."

Another frequent concern from staff members was the tone of communication in different environments and boundaries:

"Of course another ethical concern with the likes of FB is you can introduce over familiarity between two people very easily as D was saying. It is very easy to overstep that mark."

However, the majority of the group was positive about the potential benefits of using social media and one in particular offered the following distinctadvantage:

"Can I also put in a little selfish thing in that particular one as well? I feel the use of Facebook page has reduced the amount of people battering on the door looking for me. Hmm because they will put something up on FB or 
they will 'PM' me and I told them at the top of the year I was quite happy for them to 'PM' [private message] me."

While staff members were generally positive they were also (unlike the student groups) wary of potential problems including inclusion (what happens if all students do not have access to social media for course information) and litigation (several instances of inappropriate conduct and even bullying on student group pages discussed).

\subsection{Music Students}

The focus groups conducted for the Music students had a varied response to the Music staff as they were less open to the idea of lecturers seeing their online presence, particularly with social networking sites such as Facebook.

\subsubsection{HNC Music}

HNC students have frequent problems with logging into Blackboard and accessing email from home:

"When you can't log into Webmail at home, that's a problem, because there's a lot of information passed through that. If you can't access that, then it's pretty useless ... Yeah, when I'm at home I can't log in."

The concept of staff inclusion was a theme throughout the discussion relating to social media groups that have been formed between students for peer support and their apprehension to include lecturers in those groups. There were mixed views on whether students would feel comfortable using social media as an alternative to contacting lecturers directly:

"I wouldn't use Facebook Chat to talk to lecturers..."

"I did almost Tweet my lecturer this morning to say I was going to be late."

Students said they would add a lecturer as a friend on Facebook if they were socializing, but if it were purely professional then they would not engage it that manner. One solution to encourage the use of alternative ICTs in higher education, other than social media, was to ban Facebook and Twitter in the classroom, as students admit that it is a constant distraction. Another option is, rather than create a mobile app would be the integrate all ICTs into Facebook:

"For students to not use any social media as it's a distraction ... or if social media was integrated into Blackboard that would be good."

\subsubsection{Degree Music}

Degree music students again focused most of their attention on social media, as well as email and the virtual learning environment Blackboard.

"With stuff like Facebook you can create a group where you can communicate and share ideas as a class and with your tutors as well. You can get posts and everything ... same as email."

"To save large files, Blackboard's a useful tool. I think there's a lot of scope for ways that social media can be useful in higher education. In terms of communication between a class and their lecturer, it's good for maintaining constant contact, which is fairly instantaneous. Discussions can develop rapidly and be elaborated on in real time, if the interest is there with the participants."

However, they quickly highlighted the practical and ethical issues using ICTs, specifically social media, for example, lethargy and social exclusion:

"The problem might be that people end up getting caught up with the technology or some people might think 'I'll not bother coming into class because my teacher will just send me the details'." 
"If social media, or networking, becomes a large part of the learning but there are a percentage of people that aren't utilizing it, aren't included in discussions, there's a danger that they'll become alienated from the rest of the class."

One suggested solution to these issues was training and education about the appropriate use of ICTs in higher education to compliment teaching and learning:

"It actually helps, if the person doesn't know, while they are learning about a subject, they can be taught how to use the social media software."

\subsection{Social Sciences Students}

The focus groups conducted for the Social Science students were once again very different from the Social Sciences staff discussion, as students were generally hesitant of embracing social media for education, yet less aware of any serious problems such as those discussed by staff.

\subsubsection{HNC Social Sciences}

The HNC Social Sciences students were perhaps most vociferous regarding the distractions on social media sites although some would offer alternatives such as twitter:

"There can be a lot of rubbish on Facebook that sidetracks you from what you want to do ..."

"If using social networking the distractions, easy to just go and chat to someone..."

"Twitter seems a lot more educational compared to Facebook ..."

Another important concern that arose was regarding the informal nature of social media sites and whether the information would be reliable or indeed accurate:

"Because information is so quick and easy I might be tempted to go and ask a classmate rather than lecturer, the information they give me might not be correct, so I would say that is a downside to using social media ..."

Yet again the majority expressed favourable views on the ease of access, particularly in comparison to the educational technology offered by the institution:

"Easier to have a discussion on Facebook ... discussions on blackboard take a lot longer to open different replies, can see all the replies and comments."

\subsubsection{Degree Social Sciences}

Degree students were enthusiastic regarding the ease of access communicating with others via social media, and many found it useful to access course information quickly:

"I think it brings your peer group much closer together as people you may not speak that often you can easily contact through networking sites..."

"Easy to find out information quickly like exam times."

However, many were surprisingly in favour of traditional learning environments and bemoaned the distractions on offer in social media sites:

"In a better frame of mind if in a designated learning environment ..."

"Find it difficult to concentrate if working from home with distractions like Facebook ..." 


\section{Paul Oliver and Emma Clayes}

\section{Conclusions}

From the social science discussions it seems apparent that there are problems with existing technologies for education yet these may not be easily resolved by adapting social media technologies. Perhaps we need to modify existing systems to take on the best features of social media sites, particularly ease of access and more instantaneous communication. The results also reveal that we need to think more about how these technologies are used by staff and students as sometimes it seems that the intentions of educational technologies are at cross purposes from how they are actually used (students seem very reluctant to post informal queries on learning environments yet quite happy to discuss on social media sites). Results from all groups suggest user input on use of features and better guidance on purpose of tools is required to enhance the effectiveness of technology in education. It appears that many students do not view ethics as a problem, while access seems to be an issue for all.

Overall, this study suggests that students and staff have important but different views with regards to the use of ICTs in education. Access may be critical, but the most important finding from this study may be to highlight the potential problems that institutions may face with regards to ethical and practical issues. While students are unsurprisingly not aware of such issues, the fact that many staff members are also unaware is revealing and perhaps institutions should be doing more to clarify the boundaries and procedures for all. Indeed, the results corroborate previous findings regarding the enthusiasm yet confusion over the increased use of social media in education (Gikas and Grant, 2013; Veletsianos and Kimmons, 2013) and confirm these views are voiced by staff and students alike. While this study highlights important practical issues regarding accessibility, and the lack of knowledge surrounding ethical issues, the most fruitful area of research may lie in ascertaining the distinction between formal and informal learning environments (as highlighted by Deng and Tavares, 2013) in order to obtain the best of both worlds.

\section{References}

Abbruzzese, J. (2014) Facebook's 'teen problem' is more of a media problem, Mashable [Online] Available at: http://mashable.com/2014/01/02/facebook-teen-media-problem/(Accessed: $1^{\text {st }}$ March 2014)

Cain, J. and Fink, J. L. (2010) Legal and ethical issues regarding social media and pharmacy education, American Journal of Pharmaceutical Education 2010; 74 (10)

Deng, L. and Tavares, N. J. (2013) From Moodle to Facebook: Exploring students' motivation and experiences in online communities, Computers \& Education, Volume 68, Pages 167-176, ISSN 0360-1315, http://dx.doi.org/10.1016/j.compedu.2013.04.028

Eynon, R. (2005) The use of the Internet in higher education. Aslib Proceedings, Vol. 57, No. 2, pp.168-180 [Online] Available at: http://www.emeraldinsight.com/journals.htm?articleid=1465002 (Accessed: $10^{\text {th }}$ February 2014)

Garrison, G. R. and Anderson T. (2003) E-learning in the 21st century: A framework for research and practice, Routledge Publishers

Gikas, J. and Grant, M.M. (2013) Mobile computing devices in higher education: Student perspectives on learning with cellphones, smartphones \&amp; social media, The Internet and Higher Education, Volume 19, Pages 18-26, ISSN 1096-7516, http://dx.doi.org/10.1016/j.iheduc.2013.06.002.

Hew, K. F. (2011) Students' and teachers' use of Facebook, Computers in Human Behavior, Volume 27, Issue 2, March 2011, Pages 662-676, ISSN 0747-5632, http://dx.doi.org/10.1016/j.chb.2010.11.020

Khedekar, N. (2013) WhatsApp overtakes Facebook Messenger to be top mobile messaging app [Online] http://tech.firstpost.com/news-analysis/whatsapp-overtakes-facebook-messenger-to-be-top-mobilemessaging-app-108826.html (Accessed: 10th February 2014)

Kiss, J. (2014) Facebook's $10^{\text {th }}$ birthday: from college dorm to 1.23 billion users. The Guardian [Online] Available at: http://www.theguardian.com/technology/2014/feb/04/facebook-10-years-mark-zuckerberg(Accessed:10th February 2014)

Lin, H. (2007) The ethics of instructional technology: issues and coping strategies experienced by professional technologists in design and training situations in higher education. Education Tech Research Dev 55:411-437, DOI 10.1007/s11423006-9029

Neal, D. (2014) Privacy groups want FTC to investigate Facebook's $\$ 19$ billion WhatsApp buy, The Inquirer [Online] Available at:http://www.theinquirer.net/inquirer/news/2332859/privacy-groups-want-ftc-to-investigatefacebooks-usd19bn-whatsapp-buy (Accessed: 7th March 2014)

Olson, P. (2013) Teenagers say goodbye to Facebook and hello to messenger apps, The Observer [Online] Available at: http://www.theguardian.com/technology/2013/nov/10/teenagers-messenger-apps-facebook-exodus (Accessed: 1st February 2014)

Reynol J. (2012) Too much face and not enough books: The relationship between multiple indices of Facebook use and academic performance, Computers in Human Behavior, Volume 28, Issue 1, Pages 187-198, ISSN 0747-5632, http://dx.doi.org/10.1016/j.chb.2011.08.026 
Reynol J. (2013) The relationship between frequency of Facebook use, participation in Facebook activities, and student engagement, Computers \& Education, Volume 58, Issue 1, Pages 162-171, ISSN 0360-1315, http://dx.doi.org/10.1016/j.compedu.2011.08.004

Rush, D. (2014) WhatsApp: Facebook acquires messaging service in \$19 billion deal, The Guardian [Online] Available at: http://www.theguardian.com/technology/2014/feb/19/facebook-buys-whatsapp-16bn-deal (Accessed 21st February 2014)

Swan, K. (2001) Virtual interaction: Design factors affecting student satisfaction and perceived learning in asynchronous online courses, Distance Education, 22 (2), pp. 306-331 [Online] Available at: http://www.sciencedirect.com/science/article/pii/S1096751604000156(Accessed: 1st March 2014)

Tech2 (2013) Facebook in talks to buy WhatsApp [Online] Available at: http://tech2.in.com/video/whatsapp-messagingservice/922006/nJzQ19KKI4TEyL6Guoe1ppeJvK7JorSXuKi5pbiqqISlh9qr/facebook-in-talks-to-buy-whatsappreport (Accessed: 11th February 2014)

Tech Terms (2014) ICT, Tech Terms [Online] Available at: http://www.techterms.com/definition/realtime (Accessed: 7th March 2014)

Tongkaw, A. (2013) Multi Perspective Integrations Information and Communication Technologies (ICTs) in Higher Education in Developing Countries: Case Study Thailand. Procedia - Social \& Behavioral Sciences, Vol.93, pp. 1467-72 [Online] Available at: http://www.sciencedirect.com/science/article/pii/S1877042813035106 (Accessed: 10th February 2014)

Veletsianos, G. and Kimmons, R. (2013) Scholars and faculty members' lived experiences in online social networks, The Internet and Higher Education, Volume 16, January 2013, Pages 43-50, ISSN 1096-7516, http://dx.doi.org/10.1016/j.iheduc.2012.01.004. 
Paul Oliver and Emma Clayes 